\title{
Bilateral Hydrocele of the Canal of Nuck: A Rare Presentation in an Adult Female
}

This article was published in the following Dove Press journal:

International Medical Case Reports Journal

\section{Suman Baral (D) \\ Pujan Bajracharya \\ Neeraj Thapa (D) \\ Raj Kumar Chhetri}

Department of Surgery, Lumbini Medical College and Teaching Hospital, Palpa,

Tansen, Nepal

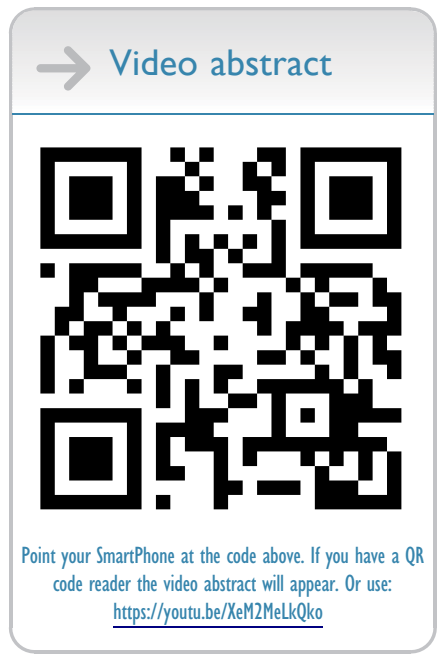

Correspondence: Suman Baral

Department of Surgery,

Lumbini Medical College and Teaching

Hospital Ltd, Tansen-07, Pravas, Palpa,

Nepal

Tel +977-75-4II 20 I

Fax +977-75-4II 202

Email brylsuman.sur@gmail.com

\begin{abstract}
Hydrocele of the canal of Nuck is one of the rarest clinical entities in the female population. It occurs due to the failure of obliteration of the processus vaginalis, which is the extension of the parietal peritoneum. Hydrocele may be seen, along with associated inguinal hernia. It usually presents with painless inguinal unilateral or bilateral swellings, and is sometimes associated with features of intestinal obstruction if the hernia becomes incarcerated or obstructed. Ultrasonography of the abdomen and pelvis and magnetic resonance imaging provide the diagnosis, if these imaging modalities are available; however, definite diagnosis may only be made during surgery. Definitive treatment includes open/laparoscopic excision of the cyst with high ligation of the neck up to the peritoneal pouch, along with repair of the inguinal hernia, if present. We present a rare case of a 25 -year-old woman who presented with bilateral inguinolabial swelling, clinically diagnosed as bilateral irreducible inguinal hernia. Intraoperatively, polycystic swelling with serous content was observed along with associated indirect inguinal hernia containing omentum on the left side. She was treated with removal of the cystic component of the bilateral canal and tissue repair of the left indirect inguinal hernia.
\end{abstract}

Keywords: hernia, hydrocele, Nuck, processus vaginalis

\section{Introduction}

Hydrocele of the canal of Nuck is not a common entity seen in the female population. The canal of Nuck is an anatomical extension of the parietal peritoneum which is accompanied by the round ligament of the uterus. If this fails to obliterate, a hernia or hydrocele may develop. ${ }^{1}$ We present the case of an adult female who presented with clinical features of bilateral inguinal hernia, which was later diagnosed as bilateral hydrocele of the canal of Nuck. Our aim is to articulate this differential diagnosis to be considered in young females with bilateral inguinolabial swellings.

\section{Case Report}

A 25-year-old woman presented to the surgery outpatient department with the chief complaint of swelling in the bilateral inguinal region for 25 days, gradually increasing in size, which had been irreducible for 1 day. It was associated with generalized abdominal pain along with nausea. However, she gave no history of abdominal distension, vomiting, or any medical or surgical interventions in the past. Clinical examination revealed irreducible bilateral inguinal swelling extending up to the labia majora, measuring approximately $5 \times 3 \mathrm{~cm}$ and $6 \times 4 \mathrm{~cm}$ on the right and left inguinal canal, respectively. Laboratory parameters were within normal limits, with stable vital signs. A preoperative diagnosis of bilateral irreducible inguinal hernia was made solely 


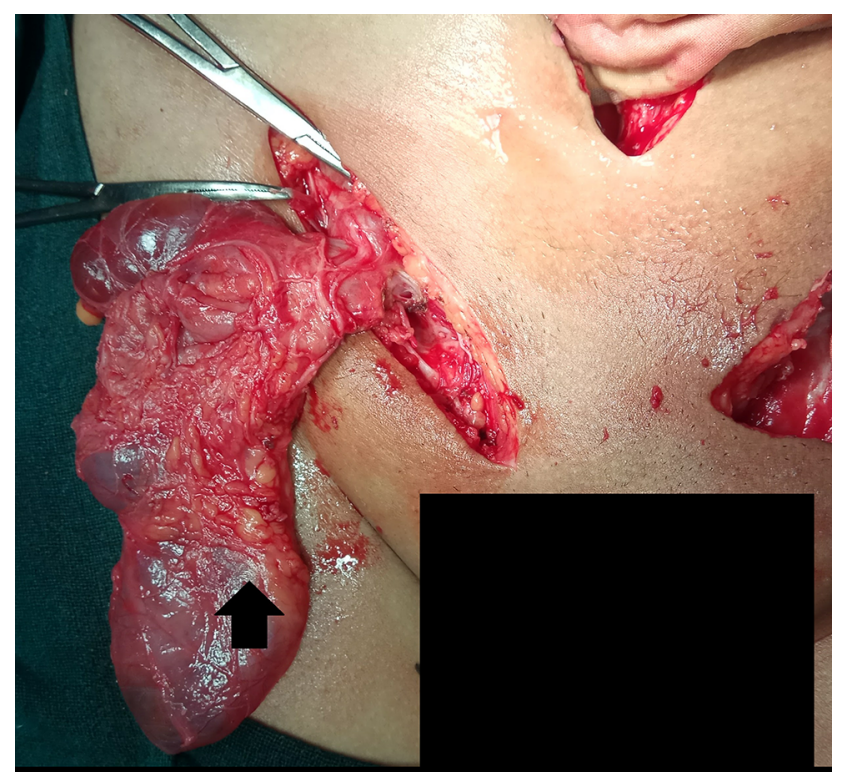

Figure I Black arrow showing a polycystic lesion in the right inguinal region along with serous fluid within, suggestive of hydrocele of the canal of Nuck.

based upon clinical judgment, as ultrasonography (USG) and magnetic resonance imaging (MRI) facilities were not available. As the laparoscopic facilities were not available during night-time, the patient was taken for open surgery. Bilateral inguinal exploration revealed a dilated canal of Nuck with encysted polycystic swelling on the right and left sides containing serous fluids along with inguinal hernia containing omentum on the left (Figures 1 and 2). The cystic lesion on the left side extended up to the deep ring, which suggested some gynecological lesion; however, intraoperative gynecological exploration found no pathology related to the uterus or ovary, which was confirmed by lower midline laparotomy. Excision of the dilated canal along with removal of the cystic component on the right side was carried out, while cystic component removal along with tissue repair of the indirect inguinal hernia was performed in the left inguinal area. The post-operative period remained uneventful. The patient was discharged on the sixth post-operative day. Histopathology was consistent with hydrocele of the canal of Nuck, with ischemic changes and inflammation (Figure $3 \mathrm{~A}$ and $\mathrm{B}$ ).

\section{Discussion}

One of the most common presentations of inguinal swelling is inguinal hernia; however, differentials do exist. As we tend to see in males with hydrocele of the spermatic cord, similarly hydrocele of the canal of Nuck can be called an analogous entity. ${ }^{2,3}$ Described by the Dutch anatomist Anton Nuck in the seventeenth century, the processus vaginalis in the

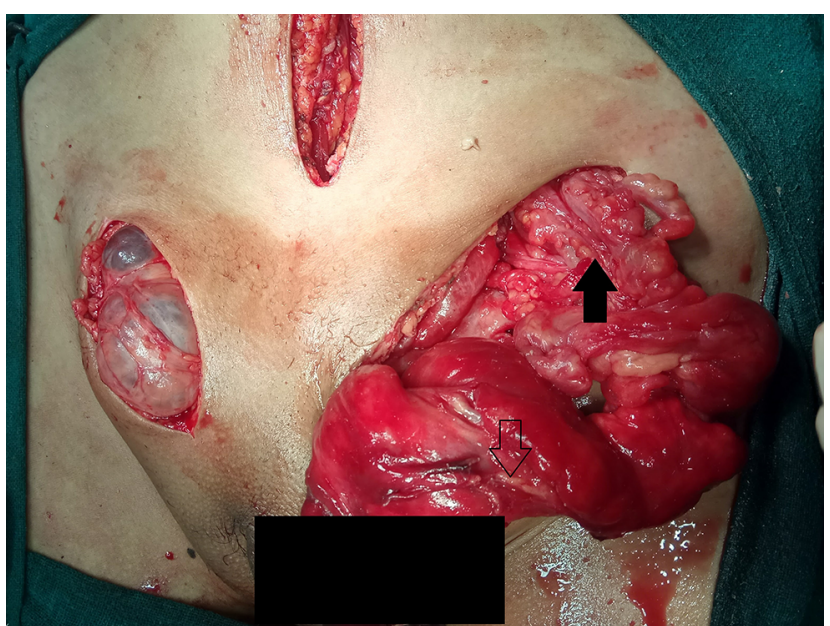

Figure 2 Incision sites in the right inguinal region, left inguinal region, and lower midline laparotomy. The black arrow pointing upward in the left inguinal area shows the omentum as a content of the left inguinal hernia; the downward arrow shows the site of the cystic component which ruptured during manipulation of the dilated canal of Nuck.

inguinal canal was named after him. ${ }^{4}$ During embryogenesis, the processus vaginalis, which is the extension of the parietal peritoneum, accompanies the round ligament up to the labia majora and is usually obliterated within the first year of life. If it fails to be obliterated, then hydrocele of the canal of Nuck develops. ${ }^{2,5}$

Anatomically, there are three types of hydrocele of the canal of Nuck described in the literature. Type 1 is similar to encysted hydrocele, which is non-communicating with the peritoneal cavity and is the most common entity. Type 2 is freely communicating with the peritoneal cavity and resembles congenital hydrocele in males, which may have associated hernia. Type 3 is the rarest form, which occurs owing to partial constriction at the deep ring that allows the distal part to descend into the inguinal canal, the proximal part being retroperitoneal. ${ }^{6}$ Our case was one of the rarest types, and probably the first of its kind owing to bilaterality of the lesion, which itself is rare, along with two varieties existing (type 1 on the right side and type 2 on the left side).

Clinically, hydrocele of the canal of Nuck usually presents with swelling in the inguinal area extending up to the labia majora, which is cystic and non-reducible, which also characterizes the features of hydrocele and this could be transilluminant. There may not be features of intestinal obstruction unless the hernia component co-exists with the bowel as the content. Hernia usually is seen if the patency is large enough to allow bowel or omentum to protrude out into the canal. ${ }^{2}$ Sometimes, the cystic swelling may be confused 
A

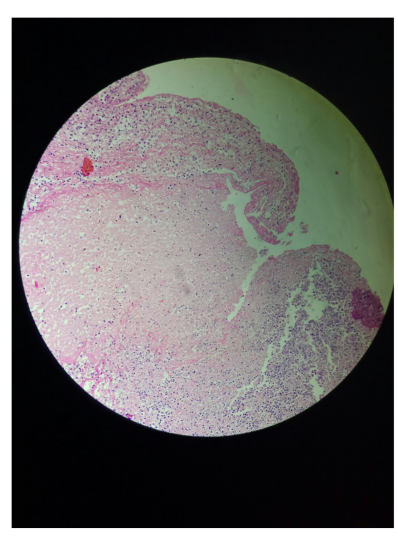

B

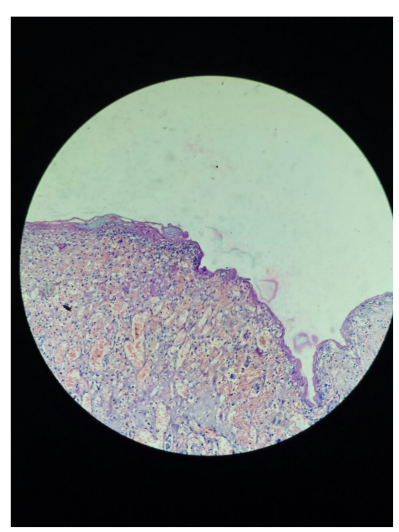

Figure 3 (A) Multiple sections examined from the bilateral inguinal region mass, with the cyst wall lined partly by flattened to cuboidal cells and partly by mesothelial cells, showing an area of necrosis with mixed inflammatory infiltrates. (B) Fibrocollagenous cyst wall lined by low cuboidal to flat epithelium along with proliferation of smallcaliber vascular channels.

with components of endometriosis if it is communicating with the fallopian tube into the peritoneal cavity via the deep ring, which happened in this case. ${ }^{7}$ So, midline laparotomy was carried out to look for endometriosis in our case.

As the lesion is superficial, USG is the preferred diagnostic modality. The lesion is typically seen as a well-defined hypoechoic or anechoic, sausage- or comma-shaped cystic mass lying superficially and medial to the pubic bone in the inguinal canal, with posterior acoustic enhancement through translucency. ${ }^{8}$ MRI findings include a well-defined, thinwalled, sausage-shaped cystic lesion, which is hyperintense on T2 and hypointense on T1 in the inguinal area. ${ }^{9}$ However, preoperative radiological investigations such as USG and MRI were not performed in this case. As per our protocol, these investigations are not mandatory for clinically diagnosed cases such as hernia or hydrocele. Also, they were not available at night.

Open exploration was planned owing to the lack of facilities for laparoscopy during off-hours. A laparoscopic approach involving transabdominal preperitoneal (TAPP) mesh repair would have been better in this case, as that would have provided direct visualization of both the deep inguinal rings and associated defects, and allowed surgical treatment of the associated hernia and removal of the cyst.

Definitive management includes open surgery, which serves as a final diagnosis and treatment. As it is commonly associated with inguinal hernia, dissection must be carried out up to the deep inguinal ring, along with high ligation of the neck of the peritoneal pouch. ${ }^{10}$ However, laparoscopic excision of a cyst with associated hernia repair has already been mentioned in the literature. ${ }^{11}$

\section{Conclusion}

To conclude, hydrocele of the canal of Nuck should be considered as one of the differential diagnoses of groin swelling in the female population. Definitive diagnosis may be made during surgery in cases where USG and MRI facilities are not available.

\section{Ethics Approval}

Ethical approval was obtained as per the guidelines of the local Institutional Review Board. The approval number was IRC-LMC 17-D/020

\section{Consent and Institutional Approval for Publication}

Written informed consent was obtained from the patient for the publication of the text and images, along with institutional approval from the Institutional Review Board, although this was not mandatory for case reports.

\section{Disclosure}

The authors report no conflicts of interest in this work.

\section{References}

1. Mandhan P, Raouf Z, Bhatti K. Infected hydrocele of the canal of Nuck. Case Rep Urol. 2013;2013:275257. doi:10.1155/2013/275257

2. Kono R, Terasaki H, Murakami N. Hydrocele of the canal of Nuck: a case report with magnetic resonance hydrography findings. Surg Case Rep. 2015;1:86. doi:10.1186/s40792-015-0086-5

3. Schneider CA, Festa S, Spillert CR, Bruce CJ, Lazaro EJ. Hydrocele of the canal of Nuck. $N J$ Med. 1994;91(1):37-38.

4. Anderson CC, Broadie TA, Mackey JE. Hydrocele of the canal of Nuck: ultrasound appearance. Am Surg. 1995;61(11):959-961. 
5. Kucera PR, Glazer J. Hydrocele of the canal of Nuck. A report of four cases. J Reprod Med. 1985;30(5):439-442.

6. McCune WS. Hydrocele of the canal of Nuck with large cystic retroperitoneal extension. Ann Surg. 1948;127(4):750-753. doi:10.1097/00000658-194804000-00018

7. Okoshi K, Mizumoto M, Kinoshita K. Endometriosis-associated hydrocele of the canal of Nuck with immunohistochemical confirmation: a case report. J Med Case Rep. 2017;11(1):354. doi:10.1186/ s13256-017-1522-x

8. Manjunatha Y, Beeregowda Y, Bhaskaran A. Hydrocele of the canal of Nuck: imaging findings. Acta Radiol Short Rep. 2012;1(3). doi:10.1258/arsr.2012.110016
9. Park SJ, Lee HK, Hong HS, et al. Hydrocele of the canal of Nuck in a girl: ultrasound and MR appearance. Br J Radiol. 2004;77(915):243244. doi: $10.1259 / \mathrm{bjr} / 51474597$

10. Wiener ES, Touloukian RJ, Rodgers BM, et al. Hernia survey of the Section on Surgery of the American Academy of Pediatrics. J Pediatr Surg. 1996;31(8):1166-1169. doi:10.1016/s0022-3468(96)90110-4

11. Qureshi NJ, Lakshman K. Laparoscopic excision of cyst of canal of Nuck. J Minim Access Surg. 2014;10(2):87-89. doi:10.4103/09729941.129960

\section{Publish your work in this journal}

The International Medical Case Reports Journal is an international, peer-reviewed open-access journal publishing original case reports from all medical specialties. Previously unpublished medical posters are also accepted relating to any area of clinical or preclinical science. Submissions should not normally exceed 2,000 words or 4 published pages including figures, diagrams and references. The manuscript management system is completely online and includes a very quick and fair peer-review system, which is all easy to use. Visit http://www.dovepress.com/testimonials.php to read real quotes from published authors. 